patients tested the laboratory isolated respiratory syncytial virus from three, and raised antibody titres were present in two patients. In the second outbreak, which also started in January and lasted for three weeks, 16 out of 40 residents in an old people's home were affected by a mild influenza-like illness with some lower respiratory tract infection. Of those affected one resident died, but this was considered to be unrelated to the illness. Fifteen residents were investigated. Rising titres were detected in three of them, and 12 had high single antibody titres. The remaining three had titres the laboratory regarded as being higher than normally expected in this age group. The source of the outbreak may have been a member of staff who had an influenza-like illness sufficiently severe to cause absence from work, and who returned to work while still unwell. Unfortunately, it was not possible to confirm a respiratory syncytial virus infection in this person, although he had a slightly raised antibody titre.

\title{
Parainfluenza infections in the elderly 1976-82
}

\author{
Compiled by the Public Health Laboratory Service Communicable Disease Surveillance Centre
}

During the seven years $1976-82$ a total of 5781 laboratory reports of parainfluenza virus infection were received by the Communicable Disease Surveillance Centre. One hundred and twenty one $\left(2^{\prime \prime}{ }^{\prime \prime}\right)$ of these reports were in people aged 65 years or older.

In the elderly $56^{\prime \prime}$ ", of infections were diagnosed by serology and $44^{\prime \prime}$ " by virus isolation; none was diagnosed by direct fluorescence, though this technique accounted for 11" " of identifications in the remainder of the population (table).
The second parainfluenza type 3 outbreak occurred in an old people's home near Preston, Lancashire. Early in June 1981 four residents developed chest infections. The home comprised five self contained units each having 10 residents. There was little interaction between residents in different units. The four residents were in one of the units and became ill with fever, dry cough, and anorexia and required bed rest. They were the only residents tested, and each test result was positive.

A further outbreak due to type 3 virus occurred in a geriatric

Method of identification of infection

\begin{tabular}{|c|c|c|c|c|c|c|c|c|}
\hline \multirow[b]{2}{*}{ Method } & \multicolumn{2}{|c|}{ Type 1} & \multicolumn{2}{|c|}{ Type 2} & \multicolumn{2}{|c|}{ Type 3} & \multicolumn{2}{|c|}{ All reports } \\
\hline & Total & Elderly & Total & Elderly & Total & Elderly & Total & Elderly \\
\hline Isolation & 1164 & 19 & 674 & 3 & 2584 & 31 & 4489 & 53 \\
\hline Direct fluorescence & 161 & & 78 & & 406 & & 647 & \\
\hline Rising titre & 79 & 13 & 3 & & 211 & 20 & 317 & 33 \\
\hline Single titre & 74 & 6 & 2 & & 273 & 26 & 370 & 35 \\
\hline Total & 1478 & 38 & 757 & 3 & 3474 & 77 & 5823 & 121 \\
\hline
\end{tabular}

Analysis of reports based on date of first specimen submitted showed that type 1 and type 2 viruses tended to peak in November while type 3 virus peaked in May or June. In the elderly, however, these peaks occurred slightly later: in December for types 1 and 2 and in July for type 3.

Of the 121 reports in the elderly, 51 were in men and 70 were in women, which probably reflects the excess of females over males in this age group.

\section{Clinical features}

About half the patients (56) had pneumonia or other lower respiratory tract infection. A quarter (37) had evidence of an upper respiratory tract infection. More elderly patients had lower respiratory tract symptoms than patients of all ages.

Five outbreaks were reported in the elderly between 1976 and 1982, one due to parainfluenza virus type 1 and four due to type 3 infection.

An outbreak of parainfluenza virus type 1 began on 4 December 1976 in geriatric wards in the Hull Health Authority. Four men had died of bronchopneumonia before specimens were obtained. Of those with symptoms, nine were positive out of 16 tested. Twenty four patients without symptoms were also tested and four were positive. The first outbreak of parainfluenza type 3, also in a geriatric hospital, began in March 1977. Symptoms included malaise, fever, and coryza and lasted for between 48 and 72 hours. The virus was isolated from three of seven affected patients who were tested. ward in a London hospital in March 1982. Twenty three patients and staff were affected over a period of one week and symptoms included coryza, malaise, sore throat, and chest infection. The virus was isolated from all seven persons tested. The last outbreak occurred among patients in a psychogeriatric hospital, several of whom were elderly, in July 1982. All had chest infections and diagnosis was serological.

At what age is it safe for a child with recurrent asthma to start using a steroid aerosol inhaler?

Clinical experience suggests that it is safe to use inhaled steroid treatment in appropriate doses of up to $200 \mu \mathrm{g}$ daily in children as soon as they are able to use an aerosol or Rotohaler effectively. In practice this is from the age of 3. There is a potential risk of some impairment of hypothalamic-pituitary-adrenal function but this will probably be of minor clinical importance if the asthma is well controlled. Local complications in children are extremely rare, there is no evidence of atopic mucosal changes with prolonged use, and thrush is rare in children. A full analysis of the use of steroids in asthma with a reappraisal in the light of inhalation treatment has recently been published with extensive discussion of the scientific and clinical experience. ${ }^{1}$-JOHN MORRISON-SMITH, honorary consultant physician, Birmingham.

Clark $\mathrm{TJH}$, ed. Steroids in asthma: a reappraisal in the light of inhalation therapy. Auckland: Adis Press, 1983. 